\title{
Nematodes in relation to plant growth. II. The influence of the crop on the nematode population
}

\author{
M. OOSTENBRINK
}

Plant Protection Service / Agricultural University, Wageningen, Netherlands

\section{Summary}

Population studies in three rotation trials demonstrated the marked influence of cropping on nematode populations in cultivated soil. One year's cultivation of different crops caused shifts in the population densities of at least four different plant parasitic nematodes in both a silt soil and a sandy soil (tables 1 and 3). The influence of one or two years' cultivation of a crop may be noticeable in the nematode infestation of subsequent crops for at least two seasons. This appears to hold for Heterodera, Meloidogyne as well as for migratory root-infesting species. Table 2 stresses the decisive influence of one-sided cultures on the appearance of different Heterodera species in a field and gives an insight into the epidemiology of Heterodera infestations and the preventative value of crop rotation.

Nine special host-parasite relationships are apparent from the tables and are summarized on p. 4 and 5 .

\section{Introduction}

The overall occurrence of a dense, mixed population of plant parasitic and saprozoic nematodes in cultivated soil was substantiated in publication I of this series (KLEYBURG and OOSTENBRINK, 1959). The density of known and suspected plant parasitic nematodes from a hundred different fields in the Netherlands ranged from 120 to 3510 , with an average of more than 900 per $100 \mathrm{ml}$ of soil; $77 \%$ of the fields contained Heterodera cysts of different kinds. The occurrence of $4-6$ genera of plant parasites, and also the occurrence of two or more species of a genus at the same place appeared to be common. The results of field trials indicated, that the density and the composition of a nematode population fluctuate markedly with the crops grown. This holds true for the plant parasites, each with its own plant-parasite relationship, and the saprozoic nematodes, which are influenced by the availability of decaying organic matter. Examples have been published earlier (OOSTENBRINK, $s^{\prime} J_{A C O B}$ and KuIPER, 1956; OostenBRINK, 1957, $1960 \mathrm{a}$ in Druck). In the following tables results of three trial fields are recorded to demonstrate the general characteristics of this population dynamics. The methods for extracting, counting and analysing of the nematodes are described elsewhere (OosTENBRINK, $1960 \mathrm{~b}$ ). Some relationships between population density of plant parasitic nematodes and the appearance of disease symptoms, or rotation effects in subsequent crops, will be reated later.

Received for publication 18th November, 1960.

Neth. J. agric. Sci., Vol. 9 (1961) No. 1 (February) 


\section{Results}

\section{A. Non-cystforming nematodes in sandy silt soil at Ellecom}

The original field was fairly uniformly infested in the spring of 1953 . The prevailing phytophagous genera were Pratylenchus, Tylenchorhynchus and Rotylenchus. Meloidogyne, Paratylenchus and some other stylet-bearing genera were present in lower numbers, Heterodera was not found here.

Corn, witloof, potato and beet were each grown on two plots of 100 sq. metres in 1953. The same crops were grown on the same plots in 1954, except potato which was replaced by carrot. In 1955 nine crops were grown on each of the original eight plots, increasing the number of plots to 72 . The nematode populations were estimated

TABLE 1. Influence of the last grown and of two preceding crops on a mixed population of root-infesting, non-cystforming nematodes in sandy silt soil at Ellecom. Four different rotations in 1953-'54. Nine different crops following each rotation in 1955.

Nematode figures determined per $100 \mathrm{ml}$ of soil in the spring of 1956. P. = Pratylenchus; $\mathrm{T} .=$ Tylenchorhynchus; $\mathbf{R} .=$ Rotylenchus; $\mathbf{M} .=$ Meloidogyne; $\mathrm{Pa} .=$ Paratylenchus; $\mathrm{O} .=$ other Tylenchida; $\mathrm{S}$. = saprozoic nematodes.

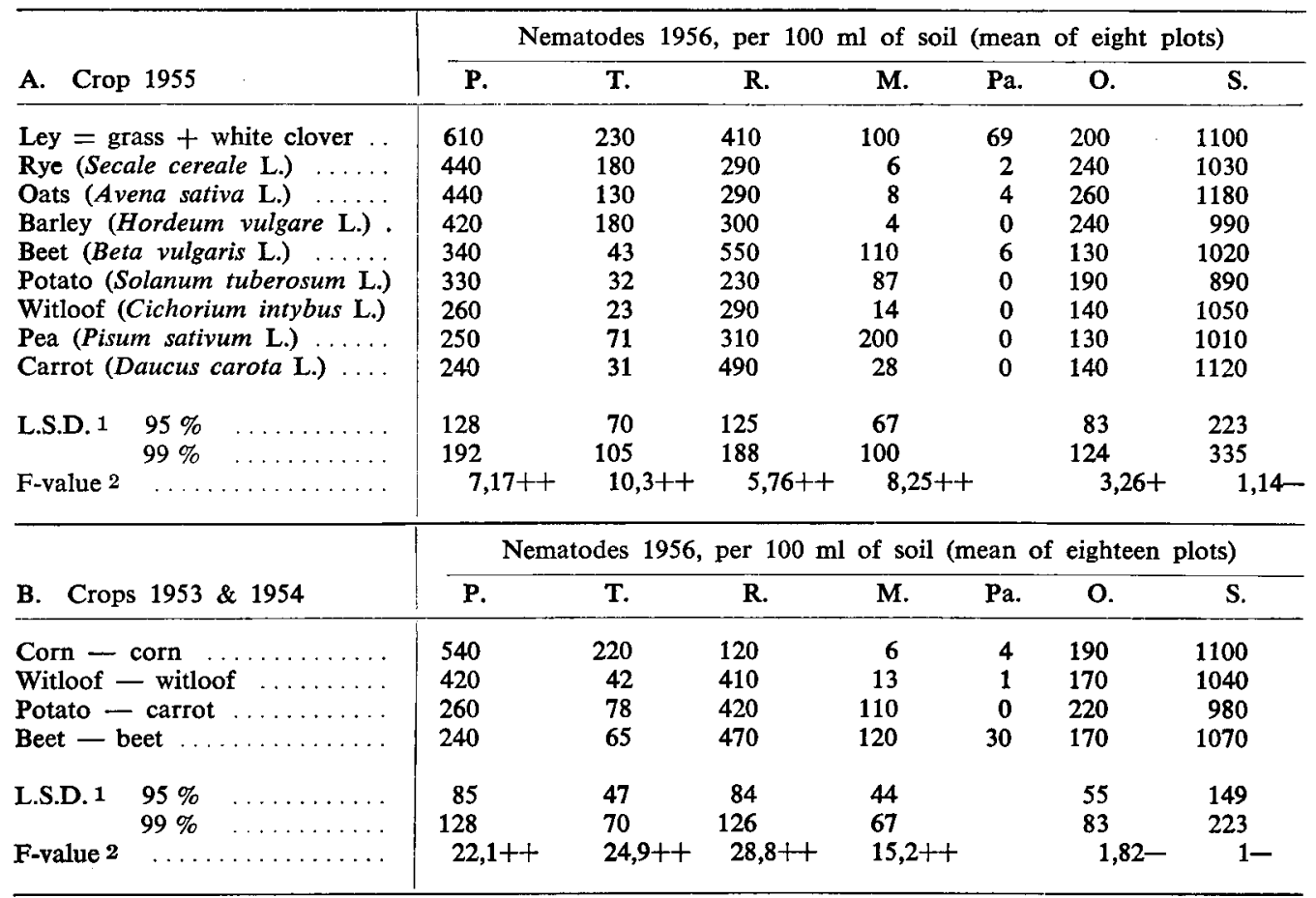

1 As least significant difference at 95 or $99 \%$ level $2 \sqrt{2}$ or $3 \sqrt{2}$ times the standard error is taken respectively.

2 Variance ratio. $++=$ differences significant at $99 \%$ level, $+=$ at $95 \%$ level, $-=$ nonsignificant. 
in soil samples from all 72 plots in the spring of 1956. They are recorded in TABLE 1 , together with general indications about statistical signifiance of the differences observed.

TABLE 1 A shows, that the population in this field comprises at least five genera to which pathogenic species are known to belong. The 1955 crops evidently have caused very significant differences in all these genera, as indicated by the F-values of the common analysis of variance. The differences in the "other Tylenchida" as a whole are barely significant, whereas the "saprozoic nematodes" as a whole do not differ in density.

Further analysis of the differences by means of the "studentized range test" in connection with the analysis of variance (KEULs, 1952) separates the crops listed in TABLE 1 into groups according to their efficiency as host plants as follows:

for Pratylenchus, mainly $P$. crenatus Loof (indicated earlier as $P$. pratensis s.l.), the crop groups are: ley — rye, oats, barley - the five remaining crops; for Tylenchorhynchus, mainly $T$. dubius (BuETsCHLI): ley - barley, rye, oats - pea - the four remaining crops; for Rotylenchus, mainly $R$. robustus (DE MAN): beet, carrot, ley five other crops - potato; for Meloidogyne, here M. hapla CHITwoon: pea - beet, ley, potato - the five remaining crops. No analysis is made of the Paratylenchus figures since too many zero's occurred, however, the range ley - beet - remaining crops is suggested. No significant differences were shown to exist by the "studentized range test" in the "other Tylenchida" and in the "saprozoic nematodes".

TABLE $1 \mathrm{~B}$, also based on the nematode figures of spring 1956, shows that the crops in 1953 and 1954 are still causing very significant differences (c.f. F.-values) after the 1955 crop in all recorded categories of root-infesting nematodes. The "studentized range test" indicates corn as an efficient host plant of Pratylenchus and Tylenchorhynchus and as a poor host of Rotylenchus, Meloidogyne and Paratylenchus. TABLE $1 \mathrm{~B}$ confirms the forementioned data of TABLE $1 \mathrm{~A}$ and stresses the indication that beet is a good host for Paratylenchus. Only witloof appears as a samewhat more efficient host of Pratylenchus than would be expected from TABLE $1 \mathrm{~A}$.

\section{B. Cyst nematodes in a sandy peat soil at Emmercompascuum}

The field was reclaimed by removing a thick peat layer in 1928 and was therefore virgin soil. Three crops of potato, two crops of wheat and one crop of rye were grown in the period 1929 through 1934. From 1935 up till the present seven different fixed cropping systems were practised on parallel plots of about 800 sq. metres in this field, viz. potatoes every year, potatoes every other year, potatoes every three years and monocultures of cereals. From the spring of 1954 on, each plot was examined annually for cystforming nematodes. TABLE 2 gives the results obtained in 1958; these results did not show real differences from those of other years.

TABLE 2 demonstrates that three cystforming Heterodera species have reached the field, viz. the cereal cyst eelworm $H$. avenae WoLLENWEBER, the potato cyst eelworm $H$. rostochiensis WOLLENWEBER and the Galeopsis cyst eelworm, H. galeopsidis GoFFART. The first-mentioned two species have built up high, in fact noxious, populations in the plots in which their respective host crops were grown intensively. Plots on which potatoes were grown every year and every other year had high nematode infestation, whereas no infestation was apparent on fields planted to potatoes every third year. Dense populations of $H$. avenae were apparent on soils planted yearly to winter wheat, oats or summer and winter cereals. $A$ dense population of this nematode also occurred in the soil planted to cereals (mainly rye) two times in three 
TABLE 2. Influence of one-sided culture on the appearance of noticeable populations of different Heterodera species in a sandy peat soil at Emmercompascuum. Seven fixed rotations since 1935. Nematode figures per $40 \mathrm{ml}$ of soil, determined in the spring of 1956.

c. $=$ cysts; vc. $=$ viable cysts; 1 . = larvae within cysts.

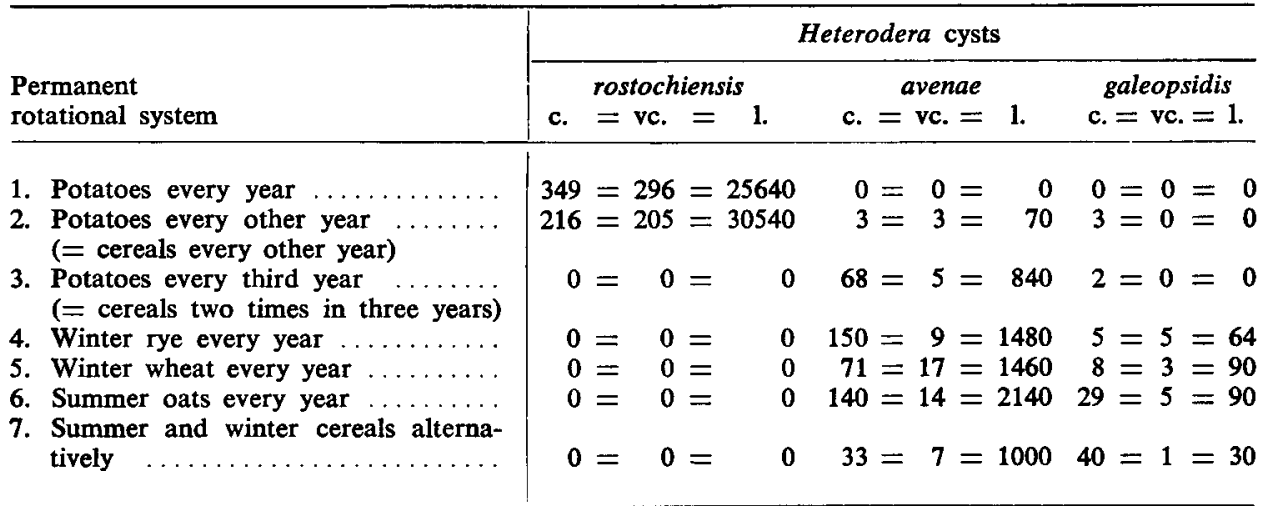

years ( $=$ potatoes every third year), but a barely susceptible population was apparent in the soil planted to cereals (mainly rye) every other year (= potatoes every other year). $H$. galeopsidis is present in noticeable concentrations in all plots except the monoculture potato plot. Host plants of this nematode, Galeopsis and Stellaria spp., are associates of the cereal culture here and occur first apparently in the plots on which cereals are regularly grown.

\section{Root-infesting nematodes in sandy soil at Alteveer}

The prevailing phytophagous nematodes in this field were Heterodera (mainly avenae), Pratylenchus (a mixture of penetrans (Совв) and crenatus), Tylenchorhynchus (mainly dubius) and Paratylenchus (an unindentified species). In 1957 four crops, viz. beet, oats, potato and rye were grown in long strips. In 1958 the same crops were again grown in strips, but at right angles to the 1957 strips. A nematode census was taken from all plots in the spring of 1959. The results are recorded in TABLE 3.

The data from TABLE 3 suggest that the density of all genera has been influenced by the crops. Pratylenchus and Tylenchorhynchus seem to be suppressed by beet. Paratylenchus, on the contrary, is stimulated markedly by beet. The densest population is found on the plot with two years beet in succession (plot nr. 3), however, the influence of the beet crop of 1957 is also noticeable on the strips with other crops in 1958 (plots nr. 1, 2, 4). Heterodera is strikingly stimulated by rye but not by oats. This is visible in the number of free larvae in the soil as well as in the number of cysts and larvae within cysts. The densest population is found on the monoculture rye plot (nr. 14). The influence of the rye crop of 1957 is, as in the case with Paratylenchus, also noticeable on the strips with other crops in 1958 (plots nr. $13,15,16)$.

\section{Discussion and conclusion}

TABLE 3 reflects the complexicity of nematode population dynamics on a sandy farm soil. The crops are common and the nematodes studied are widespread. It may there- 
TABLE 3. Influence of different rotations on a mixed population of root-infesting nematodes in sandy soil at Alteveer. Four crops in 1957, the same crops in 1958 following all crops of 1957. Nematode figures determined per 100 $\mathrm{ml}$ of soil in the spring of 1959.

HI. = free Heterodera larvae; Pa. = Paratylenchus; P. = Pratylenchus; T. = Tylenchorhynchus; $\mathbf{O} .=$ other Tylenchida; $\mathbf{S}$. = saprozoic nematodes. c. $=$ cysts; vc. $=$ viable cysts; 1 . = larvae within cysts.

\begin{tabular}{|c|c|c|c|c|c|c|c|c|c|c|c|c|}
\hline \multirow{2}{*}{$\begin{array}{l}\text { Plot } \\
\text { Nr }\end{array}$} & \multicolumn{2}{|c|}{ Crops } & \multicolumn{5}{|c|}{ Active nematodes } & \multicolumn{5}{|c|}{ Heterodera avenae cysts } \\
\hline & 1957 & 1958 & Hl. & Pa. & P. & T. & O. $+\mathrm{S}$. & c. & $=$ & vc. & $=$ & 1. \\
\hline 1 & Beet & Oats & 25 & 230 & 210 & 490 & 4260 & 38 & $=$ & 0 & $=$ & \\
\hline 5 & Oats & & 55 & 10 & 200 & 545 & 3960 & 18 & $=$ & 1 & $=$ & 20 \\
\hline 9 & Potato & & 35 & 15 & 410 & 1045 & 3850 & 23 & $=$ & 1 & $=$ & 5 \\
\hline \multirow[t]{2}{*}{13} & Rye & & 580 & 10 & 165 & 675 & 3040 & 60 & $=$ & 12 & $=$ & 290 \\
\hline & & & 695 & 265 & 985 & 2755 & 15110 & 139 & $=$ & 14 & $=$ & 315 \\
\hline 2 & Beet & Rye & 210 & 430 & 20 & 495 & 4115 & 79 & $=$ & 26 & $=$ & 1150 \\
\hline 6 & Oats & & 315 & 0 & 60 & 1030 & 3960 & 36 & $=$ & 10 & $=$ & 360 \\
\hline 10 & Potato & & 265 & 5 & 235 & 620 & 3140 & 48 & $=$ & 16 & $=$ & 795 \\
\hline \multirow[t]{2}{*}{14} & Rye & & 1190 & 15 & 230 & 1000 & 4895 & 145 & $=$ & 83 & $=$ & 3340 \\
\hline & & & 1980 & 450 & 545 & 3145 & 16110 & 308 & $=$ & 135 & $=$ & 5645 \\
\hline 3 & Beet & Beet & 25 & 3480 & 45 & 115 & 3905 & 21 & $=$ & 0 & $=$ & 0 \\
\hline 7 & Oats & & 35 & 10 & 95 & 390 & 291 & 26 & $=$ & 0 & $=$ & 0 \\
\hline \multirow{3}{*}{15} & Potato & & 10 & 0 & 15 & 280 & 3570 & 23 & $=$ & 0 & $=$ & 0 \\
\hline & Rye & & 325 & 20 & 55 & 175 & 2905 & 74 & $=$ & 30 & $=$ & 1070 \\
\hline & & & 395 & 3510 & 210 & 960 & 13290 & 144 & $=$ & 30 & $=$ & 1070 \\
\hline 4 & Beet & Potato & 160 & 135 & 240 & 585 & 407 & 21 & $=$ & 4 & $=$ & 60 \\
\hline 8 & Oats & & 45 & 25 & 195 & 520 & 457 & 17 & $=$ & 1 & $=$ & 5 \\
\hline 12 & Potato & & 30 & 5 & 115 & 425 & 3960 & 32 & $=$ & 2 & $=$ & 55 \\
\hline \multirow[t]{2}{*}{16} & Rye & & 445 & 15 & 180 & 610 & 3775 & 58 & $=$ & 16 & $=$ & 310 \\
\hline & & & 680 & 180 & 730 & 2140 & 16380 & 128 & $=$ & 23 & $=$ & 430 \\
\hline
\end{tabular}

fore be expected that these population shifts are normally occurring in practice on this soil. All four crops differ from each other with respect to one or more phytophagous species. The influence of the lastgrown crop is marked. The Paratylenchus and Heterodera figures show, that negligible populations may rise to a high level in one or two years. The same figures indicate that the influence on the nematode population of one efficient host crop may persist for more years. This was known to be true for Heterodera species, but it appears to hold true also for Paratylenchus. TABLE 1 illustrates this fact with respect to Pratylenchus crenatus, Tylenchorhynchus dubius, Rotylenchus robustus and Meloidogyne hapla. In this experiment the preceding crops were grown for two years in succession and their influence is therefore very distinct. A different cropping history may even decide about the occurrence in noticeable numbers of related species as illustrated by TABLE 2 . Initial infestations by the three Heterodera species recorded can hardly be absent in any of the plots. due to extensive distribution by wind and otherwise, but the crops had to bring them to 
the fore. This trial gives an insight into the epidemiology of Heterodera infestations and their close association with crop rotation.

Several special plant-parasite relationships become visible from the tables. Some of them are noted earlier, some others will be treated with the help of more data elsewhere. Nine cases are listed here as follows without further discussion:

a. Potatoes every year and every other year caused high populations of Heterodera rostochiensis, but potatoes every third year evidently suppressed the nematode up till now (TABLE 2).

b. Monoculture of cereals, including rye, caused high populations of $H$. avenae. Rye every other year evidently kept the nematode at a low level (TABLE 2).

c. Rye (Petkus) was an efficient host of the $H$. avenae population at Alteveer, whereas oats (Marne) was not (TABLE 3).

d. Weeds in the cereal crops, probably Galeopsis and Stellaria species, built up noticeable populations of $H$. galeopsidis (TABLE 2).

e. Ley, rye, oats, barley and corn were efficient hosts of Tylenchorhynchus dubius and of Pratylenchus crenatus (TABLES 1 and 3).

f. Beet, carrot and ley (probably the white clover component) were efficient hosts of Rotylenchus robustus in comparison to potato (TABLE 1).

g. Pea, beet, ley (white clover) and potato were efficient hosts of Meloidogyne hapla (TABLE 1).

h. Ley and beet were efficient hosts of Paratylenchus sp. (TABles 1 and 3).

i. Beet suppressed Pratylenchus, mainly penetrans, in comparison to oats, rye and potato (TABLE 3).

The examples above indicate the behaviour of some of the major species of the nematode populations present. More relationships may be present or become evident in the same soil.

\section{ACKNOWLEDGEMENTS}

The author is indebted to Ir. S. H. JUSTESEN and his co-workers of the Centre for Mathematics in Agriculture, Wageningen for statistical analysis of the data and to Dr. J. KuE of the Purdue University, Lafayette, for his help in preparing the english text.

KEULS, M.

KLEYBURG, P., and

M. OOSTENBRINK

OOSTENBRINK, M., J. J. s' JACOB, and $K$. KUIPER

OOSTENBRINK, M.

\section{LIT E R A T U R E}

1952 The use of the "studentized range" in connection with an analysis of variance. Euphytica 1, 112-122.

1959 Nematodes in relation to plant growth. I. The nematode distribution pattern of typical farm and nurseries. Neth. J. Agric. Sci. 7, 327-343.

1956 An interpretation of some crop rotation experiences based on nematode surveys and population studies. Nematologica 1 , 202-215.

1957 Das Vorkommen von Artgemischen bei pflanzenparasitären Nematoden. Nematologica 2, 342-346.

1960a Population dynamics in relation to cropping, manuring and soil disinfection. Nematology. Ed. J. N. Sasser and W. R. Jenkins, Univ. N. Car. Press, Chapel Hill. p. $439-442$.

1960b Estimating nematode populations by means of some selected methods. Nematology. Ed. J. N. Sasser and W. R. Jenkins, Univ. N. Car. Press, Chapel Hill. p. 85-102.

(in Druck) Vorfruchtwirkung und Nematoden. 